\title{
Figuración de lo que varía
}

\section{Figuration of variation}

\author{
Eduardo Andrés Carrasco Henríquez \\ CD en C. Básicas para Ingeniería. Universidad Austral de Chile. \\ ecarrasc@gmail.com \\ Leonora Díaz Moreno \\ Instituto de Matemática. Universidad de Valparaiso. \\ leonora.diaz@uv.cl. \\ Gabriela Buendía Ábalos \\ Colegio Mexicano de Matemática Educativa AC. \\ buendiag@hotmail.com
}

RESUMEN • Se presenta una investigación sobre prácticas de construcción e interpretación de una figura de entidades ostensibles y/o no ostensibles de un fenómeno de variación que llamamos prácticas de figuración. Es una aproximación de estudio de casos que indaga en contextos escolares e históricos de Oresme y de Newton, estas últimas como hitos en el desarrollo histórico de la gráfica cartesiana. Es interpretativa, pues se reúnen unas prácticas de casos científicos y estudiantiles. Es analítica en cuanto a que se identifican factores imbricados en tales prácticas. Y relacional, pues se buscan eslabones y disonancias respecto a los elementos configurados. Se comprende a las figuraciones -estudiantil e histórica- de lo que varía desde una epistemología de la figuración.

PALABRAS CLAVE: figuración; variación; gráfica cartesiana.

ABSTRACT - This article presents a research about practices of construction and interpretation of a figure representing ostensive and non-ostensive entities in a variation phenomenon. It is a qualitative case study, investigating some practices of figuration based on the Cartesian's graph historical constitution and other cases on student's productions. It is an interpretive study, since it seeks to understand figurative practices cases of scientists and other cases of student's figuration. It is analytical, since the study seeks analytical factors in figuration practices embedded in these practices. And relational, since it seeks to establish links and dissonance, regarding the elements that are being configured. We understand the student and historical figurations of what varies from an epistemology of figuration perspective.

KEYWORDS: figuration, variation, cartesian graph.

Fecha de recepción: mayo 2013 • Aceptado: enero 2014 


\section{PRÁCTICAS DE FIGURACIÓN}

El estudio que se reporta aborda la indagación de prácticas de figuración de lo que varía; esto es, prácticas de construcción e interpretación de una figura de entidades -ostensibles y no ostensibles- que se distinguen en un fenómeno de variación; por ejemplo, una práctica de figuración es la construcción de una gráfica cartesiana que se asocia a una caída libre. Esta gráfica puede figurar dos entidades que se distingan variando, tales como las magnitudes de tiempo y de distancia o de tiempo y de velocidad. La gráfica puede entonces favorecer la construcción e interpretación de la relación entre las variaciones de estas entidades.

A estas prácticas concurren el fenómeno, las figuras e intérpretes o quienes las confeccionan.

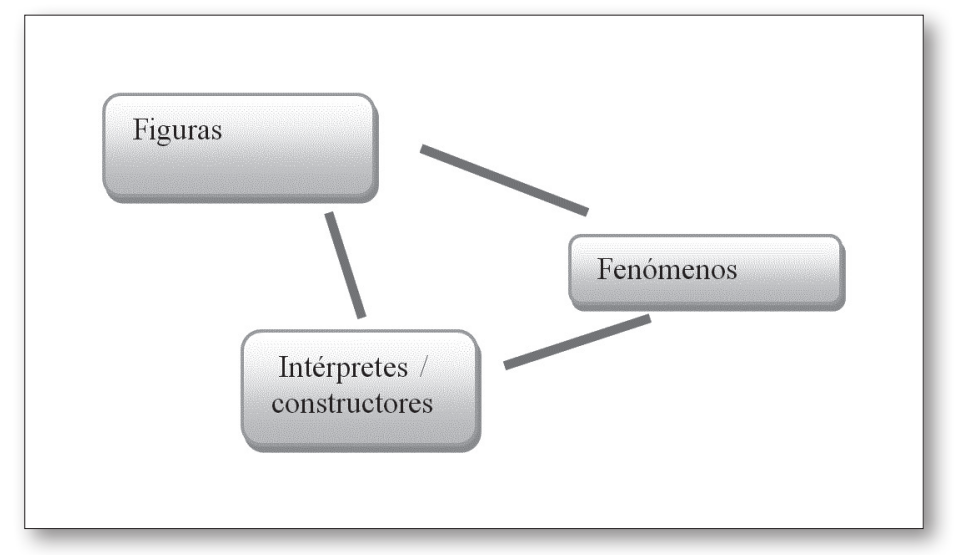

Esq. 1 Relaciones en prácticas de figuración

La figura se entiende como el conjunto de líneas que dibuja, en dos dimensiones, aspectos ostensibles y no ostensibles de un fenómeno, y se constituirá en figuración de dicho fenómeno cuando sus elementos sean significados como aspectos de este. Las prácticas de figuración enfocan la mirada al acto de figurar, es decir de construir la figura o al acto de interpretarla.

En la tradición peirceana, una figura gráfica es un conjunto de símbolos que al interpretarlos devienen signos. Signos que enlazan significados de cosas del mundo externo con el interno (Presmeg, 2008) guiando al significado de las cosas. Así, las matemáticas tendrían un carácter principalmente simbólico configurando un mundo virtual (Sfard, 2000). La figura gráfica cartesiana, por ende, porta un sistema propio de símbolos. Los estudios de su construcción e interpretación examinan sistemas particulares de significados asociados (Janvier, 1987) superando la centración en el signo matemático que, despojado de una relación a un «fenómeno», queda «atrapado» en el mundo virtual del lenguaje matemático.

Son núcleos de esta tradición el uso del signo en un sistema de símbolos, las distancias entre significados institucionales y personales y cómo esos signos presentan o interpretan una realidad externa a nuestra mente. Sin embargo, investigaciones en esta perspectiva muestran la insuficiencia de centrar los análisis y las interpretaciones en signos referidos a sistemas de símbolos.

Roth (2003) habla de transparencia de una figura gráfica cuando se alude a un fenómeno con base en la gráfica sin reparar en esta. Noss, Bakker, Hoyles y Kent (2007) muestran que la transparencia se manifiesta con matices entre los intérpretes. Ilustran tales matices entre las interpretaciones a un gráfico del ingeniero que lo construyó y del técnico que tiene contacto con la máquina, las cuales al complementarse permiten resolver problemas.

Diversos trabajos (Carrasco, 2006; Díaz, 2007a; Dolores, Chablé, Canú, Cristy y Crispín, 2009) evidencian el uso de figuraciones no cartesianas por estudiantes y profesorado. De aquí la necesidad 
de distinguir prácticas socioescolares de figuración de fenómenos (Díaz, 2012). En ellas se centra este escrito, que analiza prácticas de figuración con las que los estudiantes modelan e interpretan un fenómeno evocado y se las relaciona con los análisis de figuraciones de Oresme y de Newton. La deconstrucción de estas prácticas y su contraste aportan categorías para interpretar y comprender prácticas escolares de figuración.

\section{MARCO TEÓRICO-CONCEPTUAL}

Se asume una naturaleza de construcción social para el conocimiento matemático y una centralidad de la actividad humana en esa construcción, desde la cual la figura cartesiana es entendida como medio que propicia la actividad matemática y la construcción de saber. Al decir de Cordero, Cen y Suárez (2010), la graficación cartesiana es una práctica en el seno de diversas instituciones, entre ellas la escuela, en la que permanece y se desarrolla desde el discurso matemático escolar.

Ella favorece múltiples realizaciones para proponer relaciones que intervienen en una situación figurada. Con base en diversos argumentos, se afinan elementos involucrados y se ajusta la gráfica, desarrollando razonamiento y argumentaciones a través de justificaciones funcionales centradas en lo útil para quienes la usan. Por ejemplo, en la graficación de la función $x^{2}+$ recta, Rosado (2004) bosqueja polinomios de distintos grados mediante argumentos de linealidad gráfica. Buendía (2011) involucra a estudiantes en actividades de predicción de valores que no se ven constituyendo a la unidad periódica como argumento en gráficos de fenómenos cíclicos.

Luego no se estudia la gráfica cartesiana desde «sus partes constituyentes» o como la «representación» (en el sentido de volver a presentar) de la función, sino que se busca que ella emerja en el ejercicio de prácticas (Cantoral, Farfán, Lezama, Martínez-Sierra, 2006) configurando una epistemología de prácticas y de usos que den base de significación a la matemática escolar.

\section{El espacio epistémico de figuración}

Los estudiantes se encuentran en el aula con el docente y el saber en procesos de configuración de sus entendimientos. Cuando elaboran una figura -figurar- se hacen presentes formas de conocer y de actuar que han construido basándose en sus estructuras biológicas, dotadas de autonomía operacional e insertas en los subsistemas biológico y sociocultural. Siguiendo a Maturana y Varela (1984), el acto de conocer se comprende como la relación que entabla la persona con el medio, con los otros y con lo otro, en codefinición retroactiva entre su cognición y su entorno, a diferencia de quienes lo interpretan como una adaptación de las representaciones que se evocan y usan para generar una respuesta ante una situación.

Los sujetos aprenden desde una mente corporizada en un proceso que Varela (2000) denomina enacción. Esta noción rompe con ideas representacionistas de la mente al considerar una cognición encarnada, en la que los significados emergen al constituirse estados particulares de cooperación en las redes neuronales. Estos estados son puestos en acción -enactados- según codefiniciones retroactivas entre el sujeto y los contextos en los que vive. Así, cuando los estudiantes figuran se enactan aquellos conjuntos de ideas y acciones con base en la historia ininterrumpida de coordinaciones con los entornos, con los otros, con los que ha vivido, así como con los otros que concurren en el aula, modificándolos y modificándose en la medida en que actúan.

Parafraseando a Correa (2011), construir e interpretar figuras de fenómenos de variación pone a cada estudiante en interrelación compleja con el ambiente, con una figura y con un fenómeno, conformando un espacio epistémico de figuración que es a la vez operacional, experiencial y perceptual. En este se constituye la figuración de fenómenos de variación (esquema 2). 


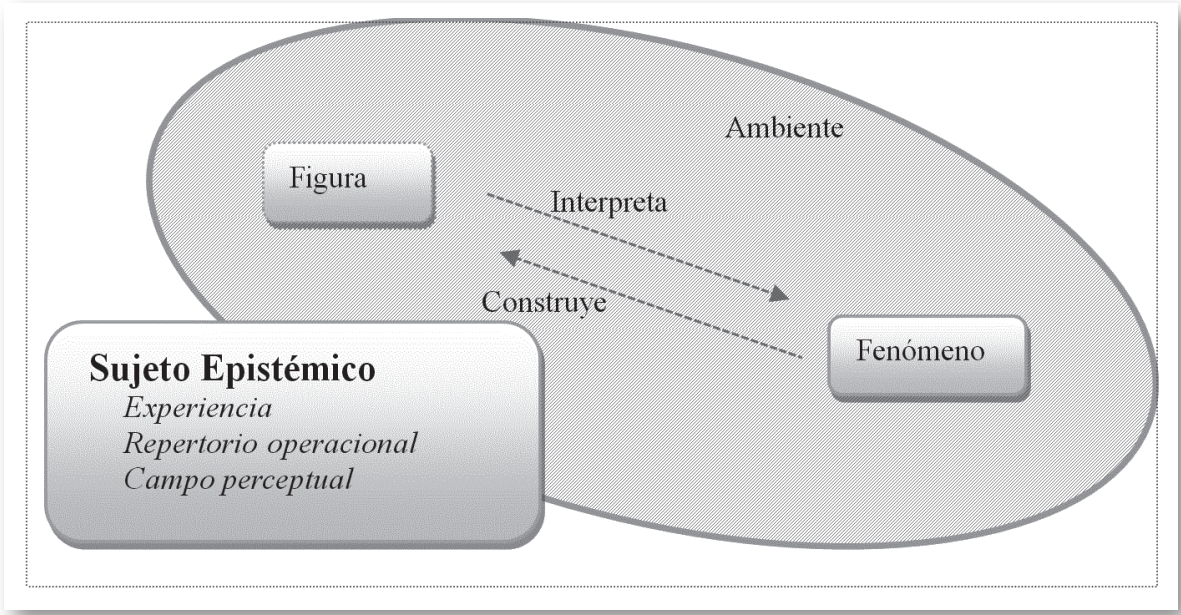

Esq. 2. Espacio epistémico de figuración.

Las figuraciones de fenómenos de los estudiantes responden a un diálogo entre actividad y mundos enactados por cada uno. Así la figuración de lo que varía será una narración de aquello que, quien figura, quiere comunicar o bien de aquello que quien observa interpreta. El estudiantado figura o interpreta imbricando su campo perceptual, su repertorio operacional y su experiencia anterior y concurrente a este acto.

En el interés de determinar lo que conforma la actividad de figurar de los estudiantes para instituir la gráfica cartesiana en herramienta de su actividad matemática, se propone deconstruir prácticas entendidas como «modos de operación o esquemas de acción socialmente compartidos» (De Certau, 2000: xli). Estas prácticas se reconocen en la acción de sujetos que forman un espacio social particular, último que coacciona a quienes no incorporan tales esquemas de acción, constituyéndolas en un hecho social en el sentido de Durkheim (2001). Y, en el aula, en una práctica socioescolar de figuración (Díaz, 2012).

\section{Elementos de las prácticas de figuración}

La práctica de figuración es discursiva, pues cada figura expresa una narración (Barthes, 1964). Y es pragmática, pues los sujetos intervienen en el fenómeno -anticipando, describiendo o prediciendodesde lo que se figura o interpreta. Luego el estudio se orienta desde la acción de quien figura y en un marco sociocultural.

La práctica de figuración recurre a herramientas. Para Vygotsky (1995), la actividad dirigida hacia una meta (que conforma al concepto) se explica en las necesidades humanas que la impulsan y en el uso de las herramientas que la permiten. Según Freudenthal (1994), los conceptos, las estructuras e ideas se crean como herramientas para organizar fenómenos del mundo físico, social y mental. Así la herramienta es central al estudio de prácticas ya que estas últimas generan herramientas que, disponibles, propician conocimiento (Ferrari y Farfán, 2008). Para este estudio son entidades que concurren con intencionalidad de uso a la práctica de figuración y cruciales para describirla.

En cuanto a los significados enactados por quienes ejercen prácticas de figuración, se sigue a Wittgenstein (1999) para quien buscar el significado de algo es buscar su uso. El significado esta mediado por el uso y la interpretación de los sujetos, por los contextos socioculturales y sus racionalidades y por las situaciones concurrentes a lo que se estudia (Espinoza y Cantoral, 2011). Así pues el significado se configura por las connotaciones, explícitas o implícitas, de los elementos presentes en cada figura. Estos se describen explicitando sus relaciones metafóricas en el acto cognitivo. 
Por su parte, las argumentaciones son andamiajes para la construcción de nuevas significaciones. Los estudiantes elaboran reflexiones para actuar y para explicarse lo que viven a partir de una narración argumentativa que les permite construir y reconstruir significados en y desde la experiencia. La argumentación, definida por Aristóteles como la acción del lenguaje a través de la cual se busca persuadir de algo a una audiencia, será apropiada si quienes la formulan y los que de ella se enteran la aceptan como tal según un criterio. A partir de este criterio, los sujetos determinan su validez (Maturana, 2001). La argumentación se entiende como expresiones narrativas o icónicas que afirman, justifican, infieren y/o concluyen sobre lo que varía.

Para interpretar la práctica de figuración se asume, parafraseando a Barthes, que la figura es una narración variacional del fenómeno figurado. Ella, desde las primeras imágenes primitivas hasta las gráficas actuales, busca hacer visible aquello que interesa y posibilita a las personas ver datos abstractos y conocer fenómenos complejos (Villafañe y Mínguez, 2002).

Toda figura se compone de elementos que se ofrecen a la exploración volitiva de quien mira. Estos se articulan en una sintaxis que, desde las propiedades perceptivas que informa la Gestalt (Costa, 2003), hacen emerger a la cognición lo que se figura. Los elementos y su sintaxis componen el relato del fenómeno. Barthes (1964) distingue tres mensajes en la figura: el mensaje lingüístico, cuyo soporte son textos y letras en la imagen que ayudan a aclarar el mensaje cuando se consideran ambiguos los elementos figurativos; el mensaje connotado, en el que los signos, al provenir de un código cultural, son interpretados por quien trabaja con la figura. Mensaje formal que es específico por estar sometido a las exigencias físicas de la visión y general, pues las «figuras» son relaciones formales de elementos, y el mensaje denotado o lo que queda en la figura cuando se borran (mentalmente) los signos de connotación. Mensaje suficiente en tanto identifica la escena figurada.

\section{METODOLOGÍA}

Este estudio interpretativo busca comprender prácticas de figuración en casos de científicos y en casos de estudiantes; es analítico al indagar factores imbricados en ellas, y relacional al buscar eslabones y disonancias respecto de los elementos encontrados. Se analiza cada práctica de figuración en el marco del caso y en su contexto sociocultural de producción. Para este artículo se seleccionan cuatro casos, los dos primeros desde producciones de estudiantes en contexto escolar, y los otros dos inscritos en la deriva histórica de la gráfica cartesiana (tabla 1).

Tabla 1.

Los casos de figuración

\begin{tabular}{|c|c|c|c|}
\hline & N. ${ }^{\circ}$ Caso & Sujetos & Figura(s) \\
\hline \multirow{2}{*}{ 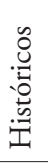 } & Casol & $\begin{array}{l}\text { Oresme. } \\
\text { Tomado de Oresme (1968) }\end{array}$ & $\begin{array}{l}\text { Variación de intensidad de una cualidad en el tiempo. } \\
\text { Demostración del teorema del valor medio. }\end{array}$ \\
\hline & Caso 2 & $\begin{array}{l}\text { Newton. } \\
\text { Tomado de Newton (2001) }\end{array}$ & $\begin{array}{l}\text { Figura de la geometría sintética, sobre cuya base desarro- } \\
\text { lla expresiones analíticas del cálculo de fluxiones. }\end{array}$ \\
\hline \multirow{2}{*}{ 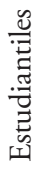 } & Caso 3 & \multirow{2}{*}{$\begin{array}{l}\text { Cuestionario exploratorio aplicado a } 26 \text { estu- } \\
\text { diantes de profesorado que ya han aprobado } \\
\text { cursos de Cálculo inicial de la carrera de Peda- } \\
\text { gogía en Educación Matemática. }\end{array}$} & Figuras de la caída de una pelota desde un tercer piso. \\
\hline & Caso 4 & & $\begin{array}{l}\text { Interpretaciones de una figura cartesiana de la evolución } \\
\text { de la población del depredador y la presa. }\end{array}$ \\
\hline
\end{tabular}

Se seleccionaron los casos históricos según su potencialidad argumental en el uso de las gráficas, la naturaleza de su figuración y la calidad del material original al que se accedió. Se interpretó el material 
desde una crónica histórica considerando el contexto social de cada autor, su biografía y su aporte a la obra matemática; con ello se construyó un relato histórico que pone a la obra en su contexto (White, 1992).

El análisis de las figuras seleccionadas fue abordado en tres niveles:

- Primer nivel. Desde lo esquemático lo que se quiere mostrar es la calidad perceptiva de los símbolos, la articulación de los elementos y los niveles de iconicidad de la figura (desde una mayor a una menor analogía con lo que se pretende figurar). Este primer análisis considera: el fenómeno que se pretende figurar; la naturaleza de los elementos que significan lo que se pretende figurar, y la sintaxis de la figura.

- Segundo nivel. El primer nivel de análisis aporta el propósito comunicativo de la figura, sus símbolos centrales y su sintaxis. A partir de ellos se reconstruye la retórica de la figura en tanto producción cultural. Se busca establecer aquellos símbolos que devienen en signos según su connotación o denotación respecto de lo que quien figura desea comunicar. Explicitar la narración de la figura lleva a establecer su estructura argumental, las herramientas que concurren a configurar la narración, y los significados que entran en juego en ella.

- Tercer nivel: eslabones y disonancias. Desde las prácticas se analizan las tramas de las narraciones en los contextos socioculturales que les dan cabida. Se reconstruyen los significados de herramientas y argumentos de las figuras, configurando unas epistemes que subyacen a las producciones figurativas. Se contrastan esas epistemes entre sí para develar eslabones y rupturas en los modos de entenderlas.

\section{ANÁLISIS DE PRÁCTICAS DE FIGURACIÓN}

\section{La figuración de lo que varía en Oresme}

En el marco de las crítica de las ideas aristotélicas sobre el estudio de la naturaleza, siglo XIV, emerge un tratamiento matemático para las variaciones de intensidad. El análisis de sentencias como «en el hombre, la caridad aumenta o disminuye, y, en épocas diferentes, es más o menos intensa» del teólogo Pedro Lombardo, abrió la posibilidad de medir lo cualitativo (Ramírez, 2007).

Oresme propone que «la intensidad expresa también la idea de que una cosa es "más esto" o "más aquello", por ejemplo, "más blanca" o "más rápida". Esta intensidad, precisamente intensidad en un punto, es divisible de una sola forma e infinitamente como un continuo. No se la puede figurar más adecuadamente, por lo tanto, que bajo la forma del continuo que es originalmente divisible y de una sola forma, es decir, por una recta» (Ramírez, 2007: 27).

La afirmación de Oresme instituye la metáfora la intensidad de la cualidad es la longitud de un segmento geométrico. Basándose en ella construye una figura geométrica en su intención de hacer un dibujo de lo que varía (Boyer, 1969). Para ello propone la figura del esquema 3: el segmento horizontal figura la duración de la presencia de una cualidad (variable en lenguaje actual) que estudia. Si es un dolor, el largo del segmento $A B$ será proporcional a la duración de la presencia del dolor. El segmento $A D$ perpendicular al segmento $A B$ en el punto inicial $A$, figura la intensidad inicial de la cualidad (dolor), mientras que el segmento $E F$, perpendicular en el punto $E$ al segmento $A B$, figura la intensidad del dolor en ese momento $E$. La razón entre las longitudes de $A D$ y de $E F$ es igual a la razón entre la intensidad del dolor en los momentos $A$ y $E$. La figura es la forma que se percibe al esbozar la mayor cantidad de líneas perpendiculares a $A B$, en este caso el cuadrilátero $A B C D$. De este modo el trapecio $\mathrm{ABCD}$, del esquema 3, figura un dolor cuyo valor en el momento inicial de la figura es distinto de cero y cuya intensidad crece de modo constante. 


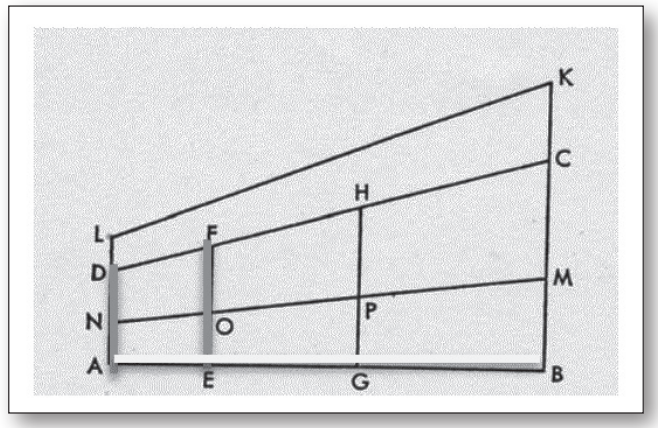

Esq. 3. Figuración de la Cualidad de Oresme (1988).

La figuración oresmiana del devenir de la intensidad de la cualidad permite nuevas acciones en el estudio de la variación o devenir de la intensidad de la cualidad. Por ejemplo, Oresme figura por medio de un triángulo el devenir de la intensidad de una cualidad que se inicia con intensidad nula y crece de modo constante (como un movimiento uniforme acelerado que inicia en reposo y llega a un valor dado) a la que llama cualidad uniforme disforme (esquema 4). Deconstruye el triángulo a partir del punto medio de la altura, lo parte y luego compone un rectángulo de igual área cuya altura es la mitad de la altura del triángulo inicial. Como el rectángulo figura el devenir de la intensidad de la cualidad uniforme, se concluye el teorema del valor medio, TVM (Oresme, 1968): la cantidad total del devenir de la intensidad de cualidades uniforme disforme figurada por el área del triángulo es equivalente a la cantidad total de la intensidad de la cualidad uniforme, figurada por el área del rectángulo, cuando su altura es la mitad de la altura del triángulo.

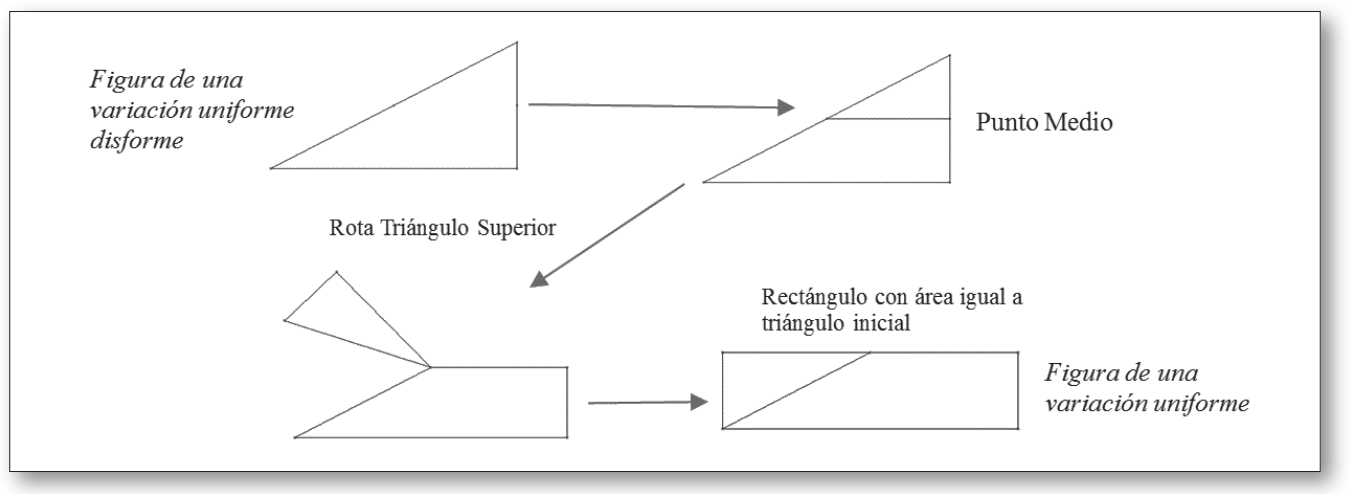

Esq. 4. Esquema de la demostración de Oresme del TVM. Elaboración propia.

Primer nivel. Oresme construye una figuración con alta iconicidad. Dota de carácter simbólico a dos figuras de la geometría euclídea: el trazo horizontal base proporcional a la duración de la variación, y cada trazo perpendicular de longitud proporcional a la medida de intensidad de la variable. La sintaxis corresponde a la emergencia perceptiva de una figura geométrica cerrada según la ley de completación de la Gestalt (acto perceptivo de completar una figura incompleta, Costa, 2003). Esta se configura con los segmentos proporcionales a la intensidad de la cualidad, barriendo la línea de base temporal.

Segundo nivel. Se inscribe a las figuras en la geometría sintética y dota a sus segmentos del carácter de herramientas de modelación de lo que varía. Emergen las significaciones de línea horizontal de base como la duración continua de la intensidad de la cualidad. En cada instante/punto se mide la intensidad, representada por un segmento perpendicular proporcional; de intensidad de la cualidad como la longitud de un segmento; de área como la cantidad total de variación de la cualidad; figura como signo 
del devenir de la cualidad. Así la narración del fenómeno «variación de la intensidad de la cualidad» se estructura en las características de la figura y su variación de altura de izquierda a derecha. Las herramientas segmento, figura, área, proporcionalidad y propiedades geométricas articulan los significados antedichos (tabla 2).

Tabla 2.

Práctica de figuración de Oresme

\begin{tabular}{|l|l|}
\hline Herramientas & $\begin{array}{l}\text { El segmento perpendicular, la proporcionalidad de segmentos, la figura, el área y los } \\
\text { procesos geométricos de trabajo con áreas. }\end{array}$ \\
\hline Argumentaciones & $\begin{array}{l}\text { A iguales áreas, igual cantidad de variación. } \\
\text { La intensidad de la cualidad es proporcional a la altura del segmento. } \\
\text { La duración de la variación de la intensidad es proporcional a la longitud de la base. } \\
\text { Descomposición de figuras para recomponerlas en otras. }\end{array}$ \\
\hline Significados/ Metáforas de base & $\begin{array}{l}\text { La intensidad de la cualidad como longitud de un segmento. } \\
\text { La cualidad como una magnitud continua. } \\
\text { La cantidad de variación como el área. } \\
\text { Distintas figuras como diferentes tipos de variaciones. }\end{array}$ \\
\hline
\end{tabular}

\section{La figuración de lo que varía en Newton}

Descartes y Fermat incorporan al estudio de curvas las potencialidades del álgebra. Descartes amplía la construcción geométrica de curvas aceptando ampliamente aquellas llamadas mecánicas por los geómetras antiguos. Estas se obtienen desde la intersección de dos o más curvas que se mueven. El punto de intersección va configurando la nueva curva. Asimismo, Descartes provee formas para determinar una ecuación algebraica que describa las relaciones comprometidas entre segmentos y/o áreas de la figura, refiriéndolas a un cierto sistema de coordenadas (Panza, 2001). Newton extiende estos desarrollos a los estudios del cambio. Expresa características del cambio por medio de curvas, líneas que no se engendran mediante la suma de partes, sino por el movimiento de puntos (Babini, 1972). Su conocimiento de la geometría de los indivisibles de Cavallieri -aprendidos en la lectura del Arithmetica Infinitorum de Wallis-, y la extensión que realiza de las operaciones aritméticas a cantidades literales concurren en su práctica de figuración. De este modo constituye a la curva como metáfora del cambio. Recurre a la proporcionalidad euclidiana para establecer primeras relaciones entre las variables. Imbrica ambas acciones y usa la noción de evanescentes para afirmar que las relaciones geométricas se mantienen al considerar cercanías infinitesimales entre elementos de la figura (Newton, 2001: 4).

En una primera figura de una situación de cambio, Newton (2001) prepara al lector para determinar la relación entre las fluxiones de dos cantidades fluyentes:

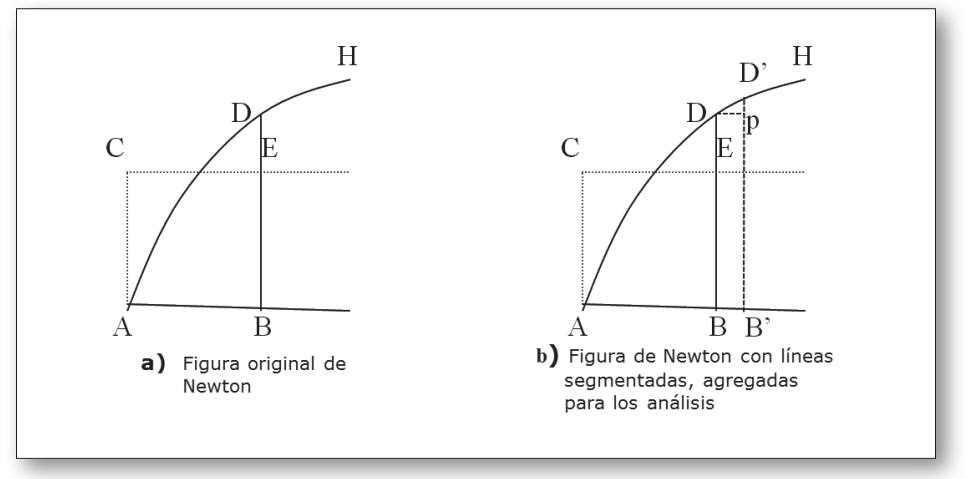

Esq. 5 Tomado de Newton 2001 
Tome la ordenada $B D$ que forma un ángulo recto con $A B$, y sea $A D H$ una curva definida por una relación entre $A B$ y $B D$ que se expresa por una cierta ecuación. Llámese $x$ a $A B$ y $z$ al área $A D B$ que está debajo de la curva aplicada a la unidad. Levántese la perpendicular $A C$, igual a la unidad, y por $C$ trácese $C E$, que es paralela a $A B$ y corta a $B D$ en $E$. Si se concibe que las dos superficies $A D B$ y $A C E B$ son generadas por el movimiento de la línea recta $B E D$, será evidente que sus fluxiones (esto es la fluxión de las cantidades $1 \times z$ y $1 \times x$, o de las cantidades $z$ y $x$ ) son entre sí como las líneas generadoras $B D$ y $B E$. Por lo tanto, se tiene que $\dot{z}: \dot{x}=B D: B E$ (o 1 ), así que $\dot{z}=\dot{x} \times B D$. De aquí resulta que $z$ podría estar involucrada en cualquier ecuación que exprese la relación entre $x$ y cualquier otra cantidad fluyente $y$, y la relación entre las fluxiones $\dot{x}$ e $\dot{y}$, podría igualmente ser encontrada.

(Ejemplo 5, problema I, Newton, 2001: 86)

Primer nivel. El esquema 5 figura la relación entre dos cantidades que covarían, $x$ e $y$, a las que llama fluyentes. Por medio de las relaciones entre las medidas de las magnitudes de la figura, analoga la covariación de los elementos de la figura a unas formas de covariar de las cantidades $x$ e $y$. Covaría longitudes de los segmentos perpendiculares $A B$ y $B D$ desplazando este a la derecha y dibujando la curva $A D H$ como traza del movimiento del punto $D$.

Newton construye el rectángulo $A B E C$ de lado unitario $A C$. Considera relevantes a $x$ como la longitud de $A B$, a $y$ como la longitud de $B D$ y a $z$ como el área bajo la curva $A D H$. Relaciona las cantidades que varían o fluyentes $x$ e $y$ desde ecuaciones a las que accede en el marco de la geometría analítica de Descartes. Basa su análisis de la variación en el desplazamiento y tamańo del trazo $B D$, haciendo visible en la misma figura distintos momentos de las variables, esto es, el cambio de las medidas de longitudes de $x$ e $y$, así como del área $z$; estas medidas las homologa por medio de la proporcionalidad a los valores de las magnitudes fluyentes $x$ e $y$ en estudio. Es decir muestra, basándose en la figura, que las cantidades fluyentes están en la misma razón que sus respectivas fluxiones o velocidades de cambio.

La estructura de la imagen y los elementos auxiliares que incorpora Newton se articulan desde los segmentos coordenados $A B$ y $B D$. Traza una curva mecánica a partir de sus cambios de longitud y de los desplazamientos del segmento $B D$, a la manera posgriega de producir curvas y ampliada por Descartes. Los griegos nominaron curvas mecánicas a las que no pudieron construir con regla y compás, por lo que no podían ser descritas a partir de los postulados, sino que debían recurrir a combinaciones de movimientos en el plano. Descartes abogará en su Geometría por la validez de estas curvas mecánicas para abordar la tarea de medir todos los cuerpos. Son curvas que se levantan generadas por un movimiento de otra curva o por combinación de varios movimientos y curvas. La figura mecánica construida por Newton se describe por las propiedades que cumplen cada uno de sus elementos, en particular por la relación de covariación entre los segmentos $A B$ y $B D$, homologable a la relación de covariación de las fluxiones (velocidades de cambio) en estudio. Es una figura simbólica al adscribirse a un concepto y es de baja iconicidad, pues figura tanto cantidades de magnitudes no ostensibles que cambian como a sus formas de covariar en el tiempo.

Segundo nivel. El esquema 5a presenta la curva $A D H$ a la vez como la traza del movimiento del punto $D$ y como la corporización de la relación de covariación de las cantidades que fluyen (varían). Esta curva es la expresión de la relación algebraica entre los fluyentes con base en los segmentos $A B$ y $B D$. Estos segmentos permiten la emergencia de las variables que fluyen al cambiar su longitud proporcionalmente a los cambios en medida de los fluyentes, y se constituyen en coordenadas geométricas.

Newton significa en los cambios de las longitudes de $A B$ los distintos momentos del movimiento del punto $D$ y, por tanto, los cambios de las cantidades fluyentes. La figura ostenta un tiempo específico en el punto $B$, el que puede variar a un tiempo $B$, junto con el cambio del valor del fluyente representado por $B D$, que varía a un nuevo segmento $B^{\prime} D^{\prime}$. En la figura se denotan tantos momentos de la variación como puntos en el eje $A B$ se identifiquen. Resulta una figura que despliega, en un mismo acto, los distintos momentos transcurridos y los correspondientes valores de los fluentes. 
En su análisis Newton relaciona los fluyentes y sus fluxiones recurriendo a «los momentos de las cantidades fluyentes, esto es, las partes infinitamente pequeñas con las cuales, al ser añadidas, incrementan en cada período infinitamente pequeño de tiempo» (Newton, 2001: 87). Los cambios se figuran en las variaciones de longitud de $A B$, infinitamente pequeñas (en el sentido de los indivisibles de Cavallieri). Son significados como cambios infinitesimales en el tiempo, evanescentes, no cero. Newton expresa el cambio (por ejemplo, el movimiento) de algún fluente particular (un móvil) digamos $x$, por el producto de su velocidad $\dot{x}$ con una cantidad infinitamente pequeńa $o$ (esto es, por $\dot{x} o$ ). Los momentos de las otras $y, z$, [...] se expresan por $\dot{y} o, \dot{z} o$ (op. cit.: 87). El cambio se significa con el indivisible formado por el segmento BB' y la longitud de PD' (esquema 5b). De este modo las relaciones entre las fluxiones se expresan por las relaciones geométricas entre los segmentos que las significan.

En suma, Newton construye una figura geométrica mecánica, como la traza de un punto que se mueve, a partir de la covariación de los segmentos coordenados. En ella despliega en un mismo acto distintos momentos, significándolos en las longitudes del segmento AB y los correspondientes valores de los fluentes, significados en las medidas de los elementos geométricos de la figura. El trabajo con indivisibles de Cavallieri le provee de herramientas geométricas para figurar cambios infinitesimales de las variables. Basándose en la proporcionalidad que ostentan elementos de la figura geométrica, relaciona las medidas de las magnitudes involucradas. Construye expresiones algebraicas que expresan estas relaciones, las cuales son significadas como las relaciones entre las medidas de los fluyentes o variables en estudio y sus fluxiones. De este modo instala un salto desde las curvas mecánicas y globales, a unas curvas que figuran diferencias o cambios locales de variables (una curvas «diferenciales») y relacionadas con expresiones algebraicas.

En la tabla 3 se presentan herramientas, argumentaciones y significados/metáforas de base que configuran la episteme de esta práctica de figuración de Newton.

Tabla 3 .

Práctica de figuración del movimiento de Newton

\begin{tabular}{|l|l|}
\hline Herramientas & $\begin{array}{l}\text { Figuras geométricas euclidianas. } \\
\text { Proporcionalidad geométrica. } \\
\text { Aritmética algebraica. } \\
\text { Figura de los evanescentes con base en los indivisibles de Cavallieri. }\end{array}$ \\
\hline $\begin{array}{l}\text { Argumentos } \\
\text { visuales }\end{array}$ & $\begin{array}{l}\text { La curva como la traza de un punto que se mueve con base en el desplazamiento de segmentos } \\
\text { perpendiculares. } \\
\text { Áreas, longitudes y sus cambios se analogan, vía proporcionalidad, a los fluyentes y sus fluxiones. }\end{array}$ \\
\hline $\begin{array}{l}\text { Significados/ } \\
\text { metáforas de base }\end{array}$ & $\begin{array}{l}\text { Las variaciones de longitudes y de áreas como variaciones de fluyentes. } \\
\text { Las fluxiones de fluyentes como variaciones de cantidades de magnitudes de elementos geométricos } \\
\text { de la figura. } \\
\text { La curva mecánica. }\end{array}$ \\
\hline
\end{tabular}

\section{Figuras estudiantiles del fenómeno de caída libre}

Se solicitó representar la caída de una pelota desde un tercer piso a 26 estudiantes de profesorado que han aprobado cursos de Cálculo inicial de la carrera de Pedagogía en Educación Matemática. La pregunta buscó dar libertad a los estudiantes para recurrir a sus herramientas gráficas al figurar el movimiento y las variables que evocan. El esquema 6 muestra figuraciones no cartesianas construidas por ellos. 


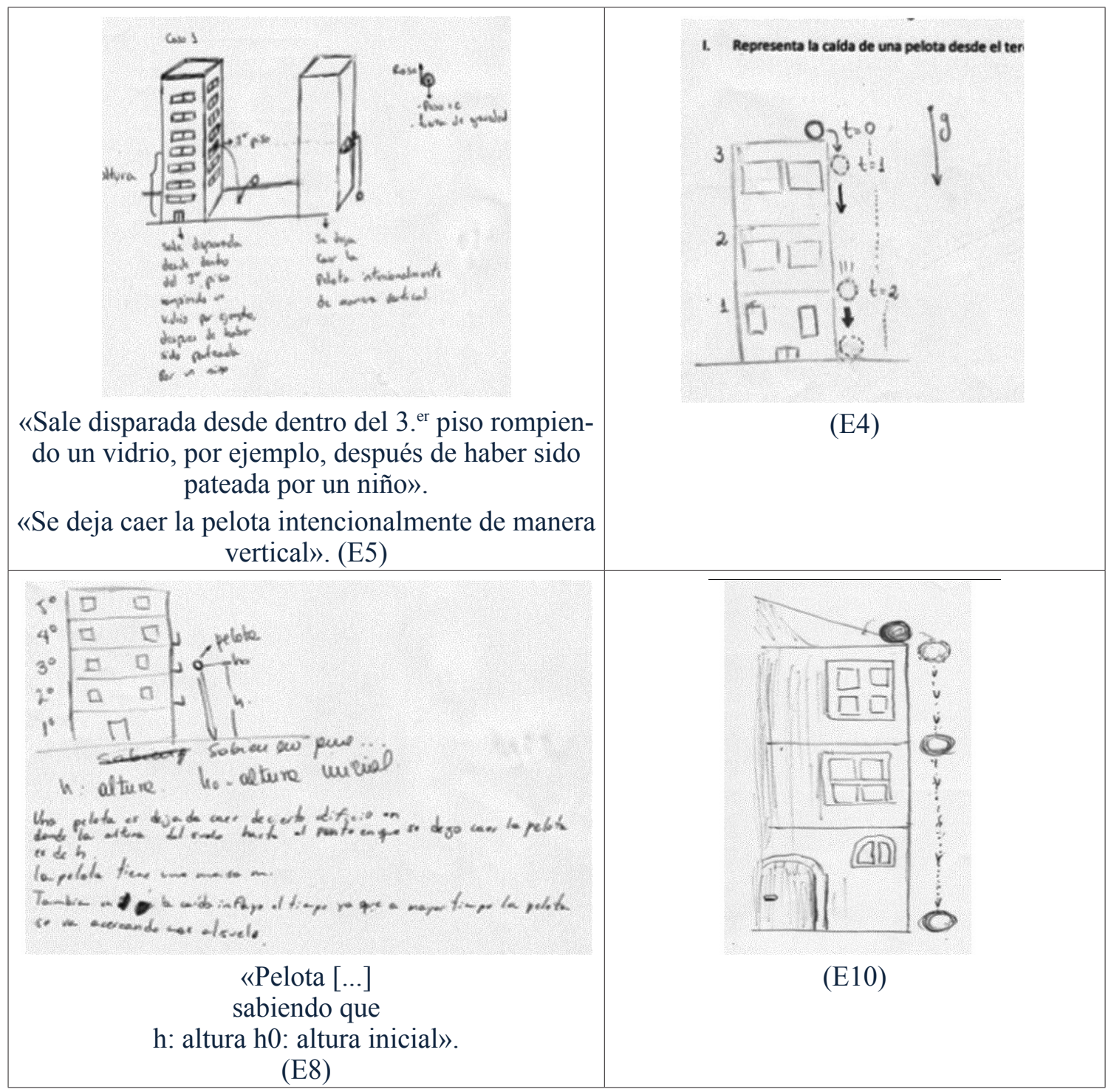

Esq. 6. Figuración de una pelota que cae.

Primer nivel. Las figuras altamente icónicas identifican relaciones espaciales, aunque alteradas, del fenómeno. Figuran la trayectoria de caída de la pelota como elemento variacional. El escenario del movimiento son el edificio y el suelo. Recurren a círculos para figurar posiciones de la pelota y a una línea para su trayectoria. Añaden símbolos físicos que presentan elementos no ostensibles del fenómeno.

La sintaxis de las figuras ostenta elementos del cómic: en el mismo escenario, las figuras E4 y E10 ilustran varias escenas en una, que distinguen con cada círculo en una posición y un tiempo específicos. Ello focaliza la mirada en la trayectoria de la pelota. Se dibuja la primera pelota con trazos bien marcados y unidos por una línea para seguir la ruta con la mirada. La altura de la pelota con respecto al edificio se connota con una letra o una llave. El tiempo se coordina con posiciones-alturas de la pelota formando diadas coordinadas como hitos cruciales que describen el movimiento de caída libre. Los símbolos físicos forman parte del fondo de la figura, siendo narrativas secundarias con respecto a la narración principal, que es la caída misma. Las textualidades aportan elementos del contexto de ocurrencia de la caída. 
Segundo nivel. El trazo que dibuja la pelota que inicia el movimiento en cada figura es grueso con respecto al que dibujan las otras pelotas o trayectoria. Ello denota esa pelota inicial como parte de la escena. Las demás, de línea tenue, se perciben fuera de la imagen a la manera de rastro de una pelota fugaz. Las diadas coordinadas (posición de la pelota, tiempo) denotan las escenas superpuestas del cómic y evidencian la posición y el tiempo en un mismo acto. La línea que une posiciones corporiza la trayectoria del móvil como guía para la exploración ocular de la figura, y se configura en un elemento dinámico. Al decir de Kandinsky (1952: 57): «La línea es la traza que deja el punto al moverse y es por lo tanto su producto. Surge del movimiento al destruirse el reposo total del punto. Hemos dado un salto de lo estático a lo dinámico». En el caso de los estudiantes, son líneas engendradas por el movimiento del centro de la pelota. Los símbolos matemáticos y/o físicos connotan factores no ostensivos que la figura no presenta, tales como gravedad y roce. Estos elementos acercan a la figura desde una función representativo-analógica a una simbólica. Las textualidades aportan información contextual, por ejemplo: «Se deja caer la pelota intencionalmente de manera vertical» (E5), que complementan a los elementos figurales en la comunicación. Las distancias entre dos lugares consecutivos de la pelota se constituyen en signos al interpretarse como el aumento de velocidad en la caída (E4 asocia intervalos de tiempo iguales con longitudes crecientes).

En síntesis, al figurar el fenómeno de movimiento propuesto a partir de la evocación de este (experimento pensado), concurren como herramientas el escenario con dimensiones espaciales (altura y horizonte) en el que se desarrolla el movimiento, la línea que orienta la exploración ocular de la figura, el símbolo de la pelota (círculo) que en sus diversas posiciones configura las diadas (posición, tiempo) que caracterizan al movimiento y al grosor del trazo que distingue elementos en acto, de los pasados o por venir. Emergen las metáforas de base de traza del movimiento en la línea, la horizontalidad y verticalidad en la hoja y la flecha como indicador de dirección; estos significados/metáforas se articulan con herramientas enseñando la trayectoria en torno a la cual denotan y/o connotan las variables que interesan. Se figura el movimiento en lo ostensible de la ruta seguida por el móvil y las diadas que marcan escenas de ella. Con una iconicidad media que se aleja de la función analógica, práctica inicial en el proceso de figurar un fenómeno.

Tabla 4.

Figuración de la caída libre por los estudiantes

\begin{tabular}{|l|l|}
\hline Herramientas & $\begin{array}{l}\text { Un escenario, con dos dimensiones espaciales (alto y ancho). } \\
\text { Flechas y líneas. } \\
\text { Grosor de la línea para diferentes posiciones en la figura. } \\
\text { Letras y vectores para connotar aspectos. } \\
\text { La lectura se hace de izquierda a derecha, y dota de un rol dinámico a la línea. }\end{array}$ \\
\hline Argumentos & $\begin{array}{l}\text { Se estructura la figura haciendo ostensible la trayectoria del objeto, colocando su inicio en el acto de } \\
\text { soltar la pelota por un sujeto y culminando con el objeto en el suelo. Alrededor de la trayectoria se } \\
\text { denotan y connotan elementos del movimiento. }\end{array}$ \\
\hline $\begin{array}{l}\text { Significados/ metáfo- } \\
\text { ras de base }\end{array}$ & $\begin{array}{l}\text { Edificio y suelo son marco para la figuración del movimiento. } \\
\text { La línea es traza de la trayectoria del móvil. } \\
\text { Flecha para informar la dirección del movimiento y como vector que denota la fuerza de gravedad o } \\
\text { el tiempo. } \\
\text { Posición coordinada de la pelota y letra } t \text {, como diadas tiempo, altura de una escena de movimiento. }\end{array}$ \\
\hline
\end{tabular}

\section{Análisis de interpretaciones estudiantiles de figuraciones de variación de dos poblaciones}

Se solicitó a grupos de tres y de cuatro estudiantes que identificaran la curva que representan las evoluciones de las poblaciones de depredador y de presa en la figura cartesiana del esquema 7 . Se con- 
jeturó que los estudiantes explorarían elementos diversos de la gráfica para la toma de una decisión y que las intervenciones a la gráfica, así como las discusiones grupales, permitirían a través de sus argumentaciones evidenciar aquello que concurre en la interpretación de esta. Se analizan las respuestas de tres grupos presentadas en los esquemas 8,10 y 12 .

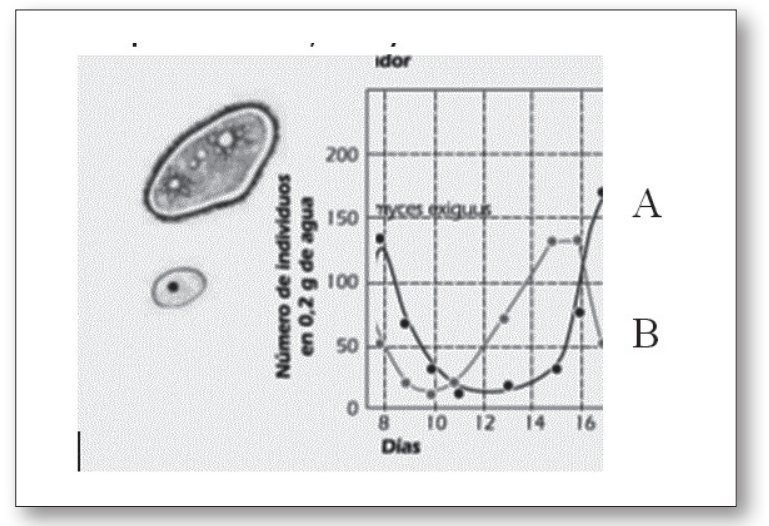

Esq. 7. Gráfica cazador-presa presentada a los estudiantes.

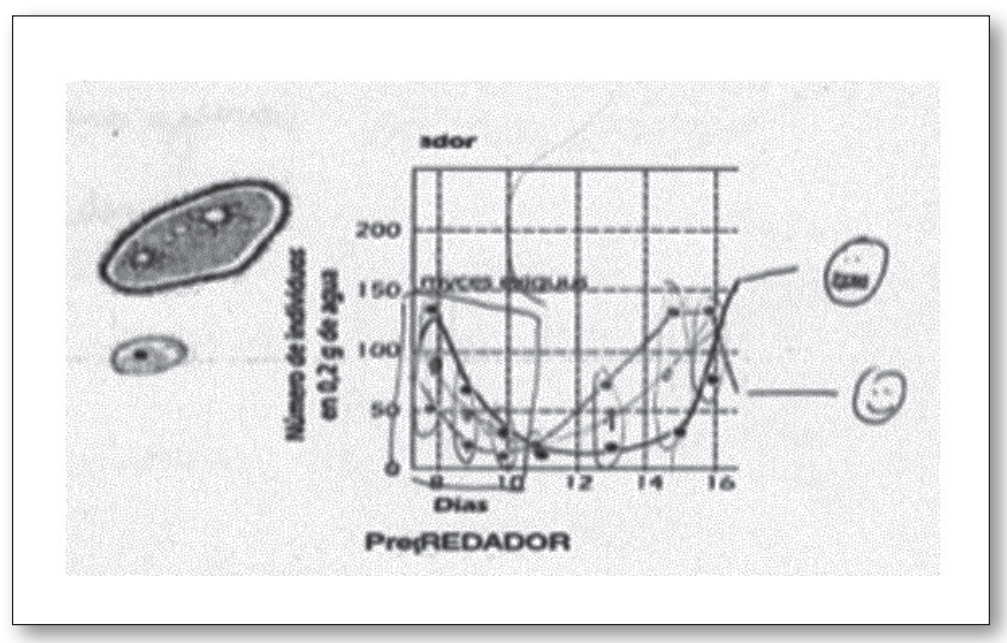

Esq. 8. Gráfica intervenida por G1.

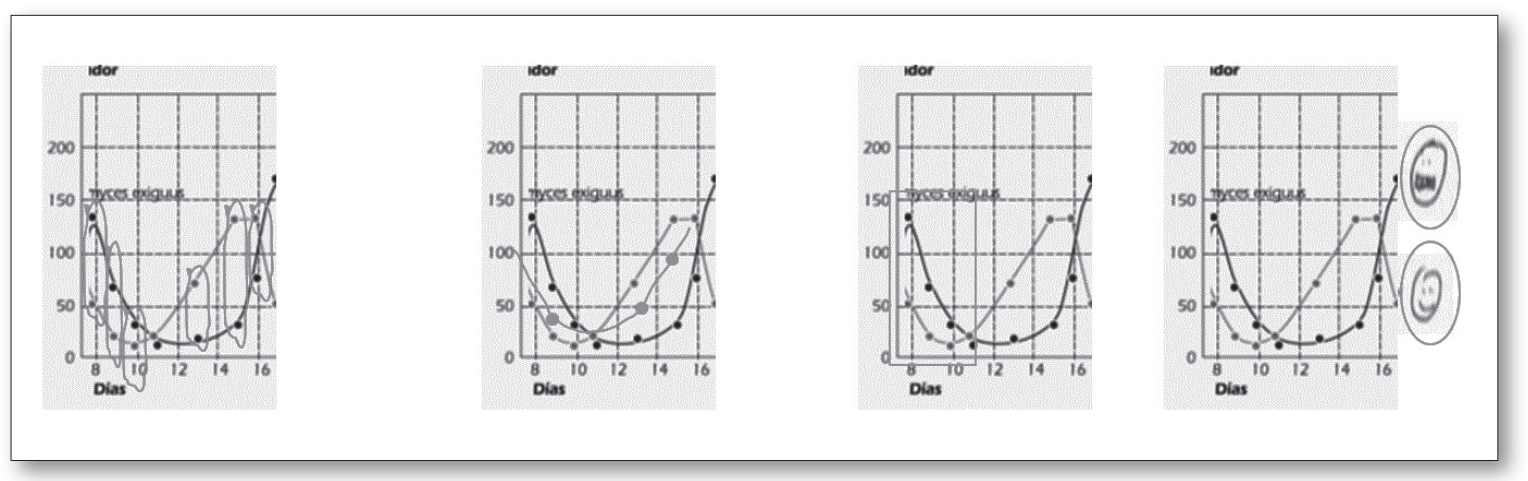

Esq. 9. Desglose de las intervenciones de G1. 


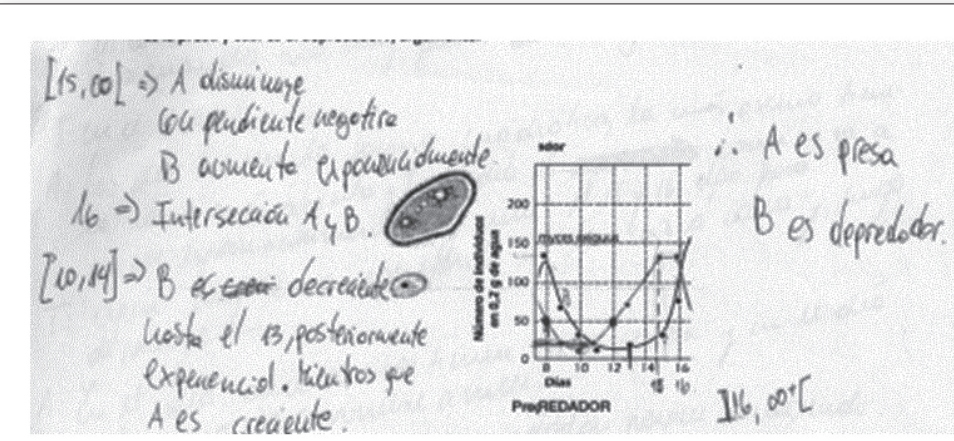

Esq. 10. Gráfica intervenida por G2

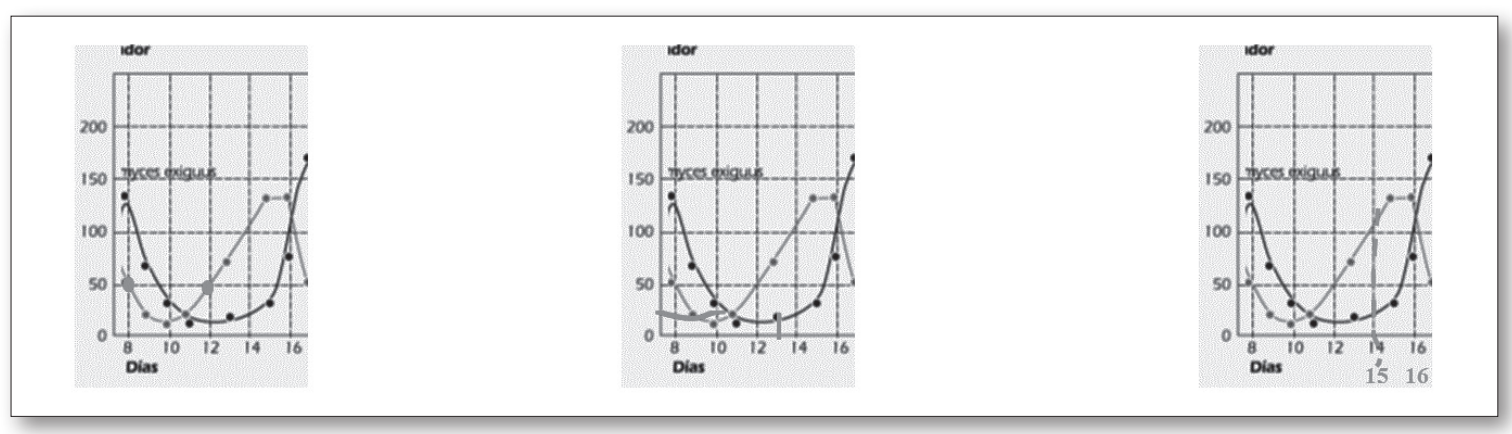

Esq. 11. Desglose de las intervenciones de G2.

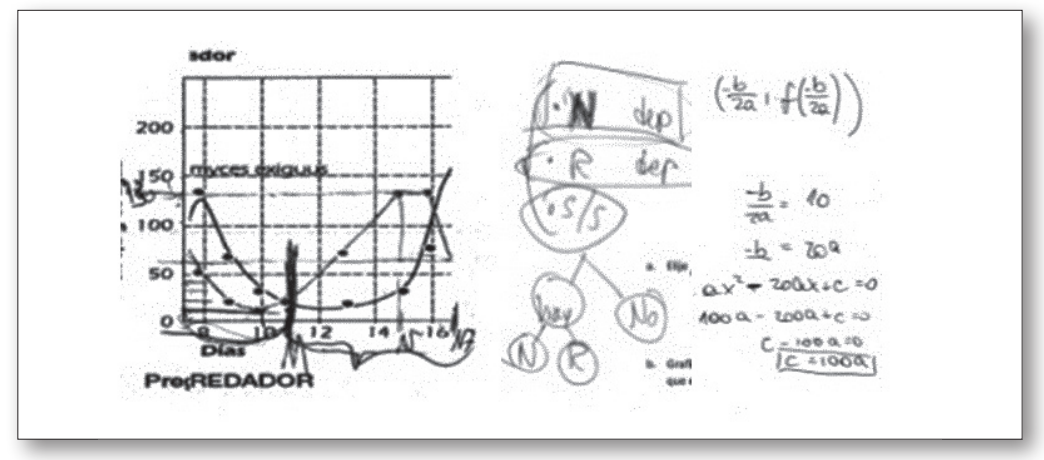

Esq. 12. Gráfica intervenida por G3.

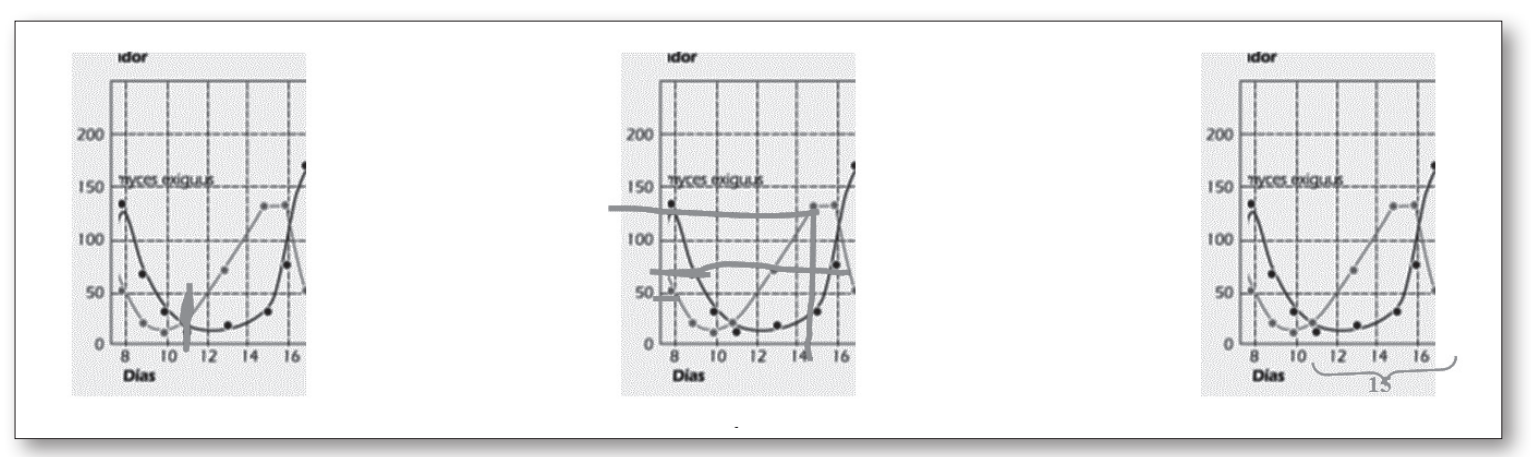

Esq. 13. Desglose de las intervenciones de G3. 
Primer nivel. Se presentan figuras cartesianas que muestran la evolución simultánea de las poblaciones presa/depredador. Ostentan elementos propios de la gráfica cartesiana: ejes perpendiculares numerados, curvas que figuran los puntos/pares de coordenadas y una sintaxis ad hoc. Con figuras geométricas, los estudiantes resaltan puntos «clave» e intervalos que juzgan relevantes y que orientan su mirada. Seleccionan como puntos «clave» aquellos en los que cambia el comportamiento entre ambas curvas o de una de ellas. Los tres grupos marcan el punto de intersección. A partir de él, las ordenadas de la curva A toman valores menores que las ordenadas de B. Marcan los puntos de cambio de monotonía de las curvas. Encierran con óvalos los puntos que se van a comparar entre las dos curvas. G1 figura una curva «media» promediando las ordenadas. Las figuras de G1 (cuadrilátero) y de G2 (llaves) contribuyen a focalizar la mirada para el análisis. A partir de estos elementos, estructuran una exploración de la figura que orienta tanto lo ocular y perceptivo como sus análisis.

Segundo nivel. Involucran sus supuestos previos de la relación depredador-presa en sus análisis. Un aumento de presas implica un aumento de depredadores y el depredador es más numeroso que la presa son los que más invocan: «lógico, es el que tiene mayores valores (depredador)» (G1); "(se) supone que cuando aumenta la cantidad de depredadores disminuye la cantidad de presas, pero cuando no hay presas disminuyen los depredadores» (G3). Luego interpretan la curva A como la población de depredadores y la curva $\mathrm{B}$ como la población de presas. Basándose en textualidades «más arriba» $\mathrm{o}$ «más abajo», dotan a la imagen de las dimensiones horizontal y vertical según cuantificaciones intensivas (Ruiz y Valdemoros, 2006). Por ello, para caracterizar los puntos clave, les basta fijar un valor de la abscisa y comparar las «alturas» relativas de sus imágenes. Su lectura del intervalo $[8,11]$ «a los 8 días había más depredadores por lo que hay menos presas» (G1) ilustra su coherencia al supuesto inicial de la curva A como depredadores. Con estas bases los estudiantes interpretan los cambios en la relación de aumento/disminución de las ordenadas de las curvas. Según los intervalos determinados por puntos clave consecutivos, construyen la narración del fenómeno figurado. Esta narración articula, en calidad de símbolos, los ejes junto con la hoja, y da lugar espacial a las curvas y sus interpretaciones; las abscisas como suelo y las ordenadas como referente de altura en la hoja; los puntos clave como cambios en el comportamiento de las poblaciones y para articular la exploración perceptiva de la mirada. Como señala Berti (1973, citado en Costa, 2003), todo cambio visual les parece significativo.

En suma, los estudiantes interpretan recurriendo a figuras auxiliares como herramientas. Sobrepuestas en la figura, separan puntos clave e intervalos de interés estructurando su exploración. Significan a los ejes como dimensiones espaciales para dar marco a un escenario en el que establecen cuantificaciones intensivas: interpretan un punto «más alto» en la imagen como un mayor valor de la variable. La situación depredador-presa enacta en los estudiantes supuestos propios respecto al fenómeno. Estos validan comparaciones intensivas de las zonas demarcadas. Articulan una argumentación que asocia una curva a la población de depredadores y la otra a la población de presas (tabla 5).

Tabla 5 .

Práctica de interpretación estudiantil de una gráfica

\begin{tabular}{|l|l|}
\hline Herramientas & Figuras geométricas que demarcan zonas para orientar la mirada. \\
\hline Argumentación & $\begin{array}{l}\text { Articular información con base en intervalos entre puntos clave y supuestos propios del fenómeno. } \\
\text { Comparar curvas con cuantificaciones intensivas de la variable cantidad de población en intervalos } \\
\text { resaltados. } \\
\text { Comparar segmentos iniciales de las curvas (mirada local) para decidir comportamientos globales. }\end{array}$ \\
\hline $\begin{array}{l}\text { Significados/ metáforas } \\
\text { de base }\end{array}$ & $\begin{array}{l}\text { La curva como una ruta en el recuadro de los ejes; } \\
\text { Los ejes como encuadre de la figura cartesiana. } \\
\text { El punto más alto de la curva como el de mayor valor de la variable de interés. }\end{array}$ \\
\hline
\end{tabular}




\section{Tercer nivel: eslabones y disonancias entre figuraciones}

La figura cartesiana emerge para hacer visible lo no ostensible a la mirada en un fenómeno de variación, la construcción de saberes se desplaza desde la geometría euclidiana como canon del trabajo matemático hacia figuraciones para visualizar y trabajar con el cambio. Oresme aborda el devenir de la intensidad de una cualidad y Newton las fluxiones de fluyentes. Oresme mira la forma global de la figura y su funcionamiento, en tanto que Newton realiza análisis locales de la figura. Para ambos, la figuración articula relaciones matemáticas de las variables.

Desde dos segmentos coordenados, Oresme y Newton construyen su figuración bajo la metáfora de la intensidad de la cualidad como un segmento geométrico. Las variaciones de longitud de los segmentos son proporcionales a las variaciones de medidas de intensidad de la cualidad en estudio. Las relaciones entre elementos de la figura son proporcionales a las relaciones equivalentes -cuando existen- en el fenómeno. Entonces la forma de la figura y las relaciones que desde la geometría euclideana se establecen en ella concurren como herramientas para significar y trabajar con el fenómeno. Oresme transforma la figura con áreas equivalentes y transformaciones geométricas. Newton establece relaciones algebraicas entre las variables figuradas a partir de una significación de lo local. Entiende la curva como la traza del punto que se mueve. Puntos cercanos en la curva resultan análogos con momentos cercanos del fenómeno, significando el dinamismo del fenómeno en la figura. Visualiza la variación infinitesimal a través de posiciones del punto, de segmentos y de áreas. Los segmentos coordenados son parte perceptiva de la figura y participan de las relaciones que en ella se construyen, a diferencia de los ejes cartesianos que dan marco a la curva (en figuraciones estudiantiles).

Las prácticas estudiantiles muestran el uso de figuras similares al fenómeno evocado. Dan cuenta de un movimiento significando la línea como su ruta. Añaden círculos o puntos que en conjunto, con la denotación textual del tiempo (letra $t$ ), forman diadas (tiempo, posición) que connotan momentos diferentes del movimiento. De un modo análogo, Newton considera puntos de la curva como momentos distintos de variación del fenómeno. Los estudiantes estructuran con una línea-metáfora del movimiento- el seguimiento ocular. Con diadas posición-tiempo, determinan diversas escenas en una figura a modo de cómic. Diadas precursoras de tabulaciones y eslabones a prácticas de numerización (Arrieta, 2003).

El escenario dibujado, un edificio en este caso, a modo de marco que estructura un suelo y una altura en la hoja, permite referencias espaciales desde la figura y comparaciones cualitativas. Esta funcionalidad también se presenta en las prácticas de interpretación. Los ejes numerados se constituyen en un marco de la figura, que es la curva, y por tanto no son parte perceptiva de la figura cartesiana. Las variables y sus escalas no son requeridas para las comparaciones. Basta señalar qué punto está «más arriba» en la hoja dotada de un horizonte y una altura. La figura no se construye ni interpreta desde la articulación de dos segmentos coordenados, sino solo desde los pares ordenados de puntos específicos. Esto deja fuera a la metáfora de Oresme en las significaciones de los estudiantes.

En la interpretación de una figura cartesiana, se deben explicitar supuestos previos. Las interpretaciones de los estudiantes se sustentaron en supuestos previos respecto al fenómeno figurado (relación cazador-presa en la variación de poblaciones) verificados en una zona demarcada por ellos en la curva, por lo que deciden qué curva corresponde al depredador. Su análisis se focaliza en la zona inicial de la curva y no lo contrastan con otras zonas de esta, e infieren para las otras zonas de la curva.

\section{A MODO DE CONCLUSIÓN}

En el horizonte de constituir a la gráfica en herramienta significativa de la actividad matemática estudiantil, se buscó, en un marco socioepistemológico, comprender prácticas de figuración cartesianas 
y no cartesianas. Prácticas entendidas como medio para comunicar y/o intervenir un fenómeno de variación, en el que la figura configura relatos que hacen visible la evolución de variables no ostensibles inicialmente.

El conocer ocurre en la relación de la persona con el medio, con los otros y con lo otro. Luego construir o interpretar figuras de fenómenos de variación se da en la relación entre observador/a, ambiente y fenómeno, y constituye un espacio epistémico de figuración que es a la vez operacional, experiencial y perceptual.

Los estudiantes constituyen un espacio epistémico de figuración que les permite significar elementos de la gráfica desde el fenómeno, a la vez que los elementos del fenómeno se evidencian y significan desde la gráfica, conformando un ir y venir entre fenómeno y figura. Concurren en sus prácticas elementos perceptivos, gráficos y propios de su experiencia con el fenómeno. Muestran la incorporación, superpuestas a la escena, de variables no ostensibles y significativas en la descripción de la variación (gravedad, tiempo, roce). Por su parte, sus prácticas de interpretación muestran la exploración activa de la gráfica, orientada por aspectos perceptivos, (figura/fondo; puntos de quiebre, entre otros) que ponen en correlación con los presupuestos sobre el fenómeno.

El análisis del espacio epistémico permitió examinar las prácticas de figuración desde las dimensiones de herramientas, significados y argumentaciones constituyendo una base de comparabilidad epistémica entre los casos estudiados. Se distinguieron categorías que, a modo de eslabones, ostentan relaciones entre las prácticas de figuración: la línea, elemento principal en figuraciones estudiantiles, se la significa como traza del movimiento, por lo que es dinámica y, como en Newton, articula la figura y la interpretación de las gráficas. Para ambas prácticas de figuración, la curva significa desplazamiento, variación. Si bien para Newton la curva como traza figura a distintas variables, para los estudiantes tiende a figurar trazas de desplazamientos.

Basándose en estos resultados, nuevos diseños didácticos podrán significar a la gráfica cartesiana desde la actividad y en el contexto de prácticas socioescolares que explicitan las facetas discursivas y pragmáticas de significados, herramientas y argumentos consignados.

\section{REFERENCIAS BIBLIOGRÁFICAS}

Arrieta, J. (2003). Las prácticas de modelación como proceso de matematización en el aula. México: Tesis Doctoral no publicada, Cinvestav.

Babini, J. (1972). El cálculo infinitesimal. Origen y Polémica. Buenos Aires: Ed. Universitaria.

Barthes, R. (1964). Ensayo: Retórica de la imagen. Paidós Comunicación.

Boyer, C. (1969). Historia de la Matemática. Madrid, España: Alianza.

Buendía, G. (2011). La construcción social del conocimiento matemático escolar. Un estudio socioepistemológico sobre la periodicidad de las funciones. México: Ediciones Díaz de Santos

Cantoral, R.; Farfán, R.M.; Lezama, J. y Martínez-Sierra, G. (2006) Socioepistemología y representación: algunos ejemplos. Relime. Número especial, pp. 83-102.

Carrasco, E. (2006). Visualizando lo que Varía. Interpretación y Construcción de Gráficas de Variación en el Tiempo. México: Tesis de Maestría no Publicada, Cicata.

Cordero, F.; Cen, C. y Suarez, L. (2010). Los funcionamientos y formas de las gráficas en los libros de texto: Una práctica institucional en bachillerato. Relime, 13(2), pp. 187-214.

Correa, M. (2011). Imagenes que podemos Tocar. Santiago: Ediciones Tecnológica Metropolitana.

Costa, J. (2003). Esquemática. Barcelona: Paidos.

De Certeau, M. (2000). La invención de lo cotidiano. Artes de Hacer. México: Inst. Tec. y de Estudios superiores de Occidente y Universidad Iberoamericana. 
DíAz, L. (2007a). Coherencias cognitivas vs matemáticas en el estudio del cambio. En: Acta Latinoamericana de Matemática Educativa. México: Clame, pp. 394-399.

Díaz, L. (2007b). Profundizando en los entendimientos estudiantiles de Variación. En R.C. Uriza, O.C. Chávez, R.M. Márquez, J.L. Andalón, y A.R. Vázquez. Investigaciones sobre enseñanza y aprendizaje de las matemáticas: un reporte latinoamericano. México: Diaz de Santos-Comité Latinoamericano de Matemática Educativa A.C., pp. 287-308.

DíAz, L. (2012). La perspectiva socioepistemológica y las comprensiones de la construcción y reconstruccion de saberes matemáticos. Mesa de Socioepistemología de la XXVI RELME. Belo Horizonte, Brasil.

Dolores, C.; Chablé, A.; Canul, E.; Cristy, C. y Crispín, P. (2009). De las descripciones verbales a las representaciones gráficas. Union, Revista Iberoamericana de Educación Matemática (18), pp. $41-57$.

Durkheim, E. (2001). Las reglas del Método Sociológico. México: Fondo de Cultura Económica.

Espinoza, L. y Cantoral, R. (2011). Una caracterización de los contextos de significación desde la socioepistemología. ALME, 24, pp. 889-895.

Ferrari, M. y Farfán, R.M. (2008). Un estudio socioepistemológico de lo logarítmico: la construcción de una red de modelos. Relime, 11(3), pp. 309 - 354.

Freudenthal, H. (1994). Fenomenología didáctica de las estructuras matemáticas. (L. Puig, Trad.) México: Departamento de Matemática Educativa del Cinvestav.

Janvier, C. (1987). Problems of representations in the teaching and learning. Hillsdale, NJ, England: Lawrence Erlbaum Associated.

Kandinsky, N. (1993). Punto y línea sobre el plano. Contribuiciones al análisis de los elementos pictóricos. Colombia: Labor S.A.

Maturana, H. (2001). Emociones y Lenguaje en Educación y Politica. Santiago: Ed. Dolmen.

Maturana, H. y Varela, F. (1984). El árbol del conocimiento. Santiago, Chile: Editorial Universitaria.

Newton, I. (2001). Tratado de Método de Series y Fluxiones. (I. Vargas, Trad.) México: Servicios editoriales de la Facultad de Ciencias, UNAM.

Noss, R.; Bakker, A.; Hoyles, C. y Kent, P. (2007). Situating graphs as workplace knowledge. Educational Studies in Mathematic (65), pp. 367-384.

Oresme, N. (1968). Tractatus de configurationibus qualitatum et motuum. English translation, and commentary by Marshall Clagett.Madison, Wis. Univ. of Wisconsin Pr.

Panza, M. (2001). Introducción. En I. Newton. Tratado de Métodos de Series y Fluxiones (I. Vargas, Trad.). México: Servicios editoriales de la Facultad de Ciencias, UNAM, pp. 1-54.

Presmeg, N. (2008). An overarching theory for research in visualization in mathematics education. ICME 11. Recuperado el 15 de Septiembre de 2010, de <http://tsg.icme11.org/document/get/97>.

Ramírez, J. (2007). Reflexiones sobre las ideas de Nicolás Oresme. Revista de Historia de la Medicina $y$ de la Ciencia, V. LIX, pp. 23-24.

Rosado, P. (2004). Una Resignificación de la derivada. El caso de la linealidad del polinomio en la aproximación socioepistemológica. México: Tesis de maestría no publicada. Cinvestav.

Roth, W.-M. y Bowen, G. (2003). When Are Graphs Worth Ten Thousand Words? An ExpertExpert Study. Cognition and Instruction, pp. 429-473. http://dx.doi.org/10.1207/s1532690xci2104_3

Ruiz, E. y VAldemoros, M. (2006). Vínculo entre el pensamiento proporcional cualitativo y cuantitativo: el caso de Paulina. Relime, 9(2), pp. 299-324.

SFARD, A. (2000). Symbolizing mathematical reality into being: How mathematical discourse and mathematical objects create each other. En K.E.P. Cobb. Symbolizing and communicating: perspectives on Mathematical Discourse, Tools, and Instructional Design. Erlbaum, pp. 37-98. 
Varela, F. (2000). El fenómeno de la vida. Santiago: Noreste Ltda.

Villafañe, J. y Mínguez, N. (2002). Principios de Teoría General de la Imagen. Madrid: Ed. Pirámide. Vygotsky, L.S. (1995). Pensamiento y lenguaje. Teoría del desarrollo cultural de las funciones psíquicas. (M. Rodger, Trad.) Buenos Aires: Ed. Fausto.

White, H. (1992). Metahistoria. La imaginación historica en el siglo XIX. México: Fondo de Cultura Económica.

Wittgenstein, L. (1999). Investigaciones filosóficas. (U. M. Alfonso García, Trad.) Barcelona: Atalaya. 


\title{
Figuration of variation
}

\author{
Eduardo Andrés Carrasco Henríquez \\ $\mathrm{CD}$ en $\mathrm{C}$. Básicas para Ingeniería. Universidad Austral de Chile. \\ ecarrasc@gmail.com \\ Leonora Díaz Moreno \\ Instituto de Matemáticas. Universidad de Valparaíso. \\ leonora.diaz@uv.cl \\ Gabriela Buendía Ábalos \\ Colegio Mexicano de Matemática Educativa AC. \\ buendiag@hotmail.com
}

This paper presents a research about practices of construction and interpretation of a figure of ostensive or no ostensive entities in a phenomenon of variation, which we called practices of figuration. For example, the cartesian graph (mathematical figure) of a free fall phenomenon could represent the ratio of the variation between time and distance.

A figure is a set of lines and points. It becomes the figuration of the phenomenon when a student gives meaning to its elements as specific aspects of the related phenomenon. The figuration practice is constituted in the set of relations between the phenomenon, the figure and the student (or students) who is interpreting this figure.

We use elements from Varela, from the Theory of Image and from Barthes semiotic. These elements are articulated in a socioepistemological framework which proposes that mathematical knowledge is a sociocultural construction normed by social practices.

First, we understand the cognitive act through enaction. When students are performing a task, their world experience emerges, along withe their interaction with other people and in their interaction with the situation and the phenomenon. In particular, when they make or interpret a graphic, a geometrical world for interpreting the elements of the figure, the phenomenon's world or a blend of these worlds could emerge in their cognition. Thus, the student, the figure and the phenomenon configure one epistemic space of figuration.

Secondly, the figure is a variation narrative of the phenomenon studied; it helps in making visible any interesting aspect of phenomenon. It allows to see abstract data and visualize complex phenomena.

Therefore, when any person makes or interprets one figure he or she uses his or her perceptual field, his or her operational repertoire and his or her prior experience. To characterize these figuration practices, we described: the tools used as entities that concur intentionally to the activity; the meanings enacted in the activity as a connotation, explicit or no explicit, of the elements present in the figure; the argument, which is understood as a narrative or iconic expression used to explain, justify or infer about the variation of the variables depicted.

This is an interpretive study, since it seeks to understand figurative practices in Newton, Oresme and two study cases of students. It is analytical since the study seeks analytical factors in figuration practices embedded in students and historical practices. And finally, it is a relational one since it seeks to establish links and dissonances regarding the elements that are being configured. We analyzed the practice of figuration in each study case within the framework of the sociocultural context of production. The data is obtained from the written production of each actor. In the historical case, we studied the original production. In the students' case, we studied answers from specific questions.

The results obtained show the convenience of using these theoretical tools for characterizing the practice of figuration and its elements. We find evidence that non-cartesian figures produced by the students are dynamically configured. Also, perceptual and graphical elements concur within student activity and phenomena. In the interpretation practice, the students explore correlating perceptual aspects with the preconceptions about the phenomenon. 